\section{Cellular and plasma fibronectin in the aqueous humour of primary open-angle glaucoma, exfoliative glaucoma and cataract patients}

MINNA VESALUOMA, PÄIVI MERTANIEMI, SARI MANNONEN, ILKKA LEHTO, RISTO UUSITALO, SEPPO SARNA, AHTI TARKKANEN, TIMO TERVO

\author{
M. Vesaluoma \\ I. Lehto \\ R. Uusitalo \\ A. Tarkkanen \\ T. Tervo \\ Department of \\ Ophthalmology \\ Helsinki University Eye \\ Hospital \\ Finland

\section{P. Mertaniemi \\ S. Mannonen \\ Genex Oy \\ Helsinki \\ Finland \\ S. Sarna \\ Department of Public Health University of Helsinki \\ Finland}

Minna Vesaluoma, MD, PhD Department of

Ophthalmology

Helsinki University Central

Hospital

PO Box 220

FIN-00029 Huch

Finland

Tel: 35894713168

Fax: 35894715569

e-mail: minna.vesaluoma@huch.fi

\section{Abstract}

Purpose To compare the concentrations of cellular fibronectin (cFN), plasma fibronectin (pFN), tenascin and calcitonin gene-related peptide (CGRP) in the aqueous humour in primary open-angle glaucoma (POAG), exfoliative glaucoma (EXFG) or cataract (control group).

Methods The concentrations were determined by enzyme-linked immunoassays in the aqueous humour of patients with EXFG $(n=26)$, POAG $(n=29)$ or cataract (control group, $n=13$ ).

Results The pFN concentrations of the three patient groups differed significantly from each other $(p=0.0004$ in a non-parametric analysis of variance). In multiple comparisons EXFG patients showed significantly higher $\mathrm{pFN}$ levels than POAG patients $(p<0.05)$ or cataract patients $(p<0.01)$. The cFN level was also significantly higher in EXGF patients than in POAG patients $(p<0.05)$ or cataract patients $(p<0.05)$. The pFN or $c F N$ concentrations of the POAG group did not differ from those of the control group. Neither tenascin nor CGRP was detected in the aqueous humour of any of our patients.

Conclusions The significantly higher aqueous humour pFN concentration in exfoliative glaucoma may be a consequence of disruption of the blood-aqueous barrier and may further add to an increased outflow resistance.

Key words Aqueous humour, CGRP, Exfoliation, Fibronectin, Glaucoma, Tenascin

The biological changes behind various forms of primary open-angle glaucoma (POAG) are largely unknown. The extracellular matrix of the trabecular meshwork, however, is a likely site for the increased outflow resistance responsible for intraocular hypertension.
Deposits of exfoliative material may further block the aqueous outflow channels in the trabecular meshwork, resulting in elevation of intraocular pressure and exfoliative glaucoma (EXFG).

Several glycoproteins and proteoglycans have been encountered in the extracellular matrix of the trabecular meshwork.

Extracellular matrix components such as fibronectin (FN), ${ }^{1,2}$ tenascin, ${ }^{3,4}$

thrombospondin, ${ }^{5}$ laminin and various collagen types, ${ }^{2}$ as well as elastin, ${ }^{6,7}$ have been identified in the outflow drainage system. The possible role of each protein in the regulation of outflow resistance or development of POAG is not clear. It has also been shown that the aqueous humour of patients with POAG is capable of inducing increased collagen synthesis, ${ }^{8}$ which may have a role in the pathogenesis of POAG.

FN is an adhesive extracellular glycoprotein; plasma FN (pFN) is produced in liver, ${ }^{9}$ and the cellular form ( $\mathrm{cFN})$ is produced locally in developing or regenerating tissues. ${ }^{10,11} \mathrm{An}$ extradomain A (EDA) sequence is contained in cFN and distinguishes it from $\mathrm{pFN} .{ }^{10}$ Deposits of FN detected in the inner wall of Schlemm's canal and the juxtacanalicular or cribriform parts of the trabecular meshwork seem to increase with age, and apparently correlate with the progression of POAG. ${ }^{12}$ Cultured trabecular meshwork cells have been shown to be capable of secreting all major extracellular matrix constituents of the trabecular meshwork, including FN. ${ }^{13}$ Tenascin, another extracellular matrix glycoprotein, is present during embryogenesis and in diverse malignant tumours, suggesting that it has a modulatory role in cell growth and tissue remodelling. ${ }^{14,15}$ Tenascin is also expressed during corneal wound healing ${ }^{16,17}$ and, unlike FN, has been shown to be present only in the inner and outer walls of Schlemm's canal. ${ }^{4}$ 
Calcitonin gene-related peptide (CGRP) is a neuropeptide of 37 amino acids that has been localised to sensory neurons, including those in the anterior segment of the eye. ${ }^{18}$ Several animal studies have been conducted to clarify the effects of intracameral CGRP on intraocular pressure. ${ }^{19-24}$ To our knowledge, there are no human studies concerning the occurrence of CGRP in the aqueous humour or its role in the regulation of intraocular pressure.

Kim et al. ${ }^{25}$ have reported that glaucoma patients have significantly higher aqueous humour FN concentrations than cataract patients. Our aim was to elucidate whether $\mathrm{FN}$ in aqueous humour is $\mathrm{cFN}$ or $\mathrm{pFN}$. The tenascin levels were measured because of the similarity of tenascin to FN in the expression or response to various stimuli. Furthermore, as a potential compound affecting intraocular pressure, CGRP concentrations were also investigated.

\section{Materials and methods}

\section{Patients}

Altogether 68 eyes of white Finnish patients (48 women and 20 men; mean age of 71.9 , SD 10.2 years, range 46-92 years) were included in this study. The research followed the tenets of the Declaration of Helsinki. Group 1 included patients with EXFG ( $n=26$; mean age 75.3, SD 8.5 years, range $60-92$ years), group 2 patients with POAG $(n=29$; mean age 69.4, SD 10.8 years, range $46-85$ years) and group 3 patients with senile cataract ( $n=13$; mean age 70.5, SD 10.9 years, range $49-84$ years). None of the patients in group 3 had glaucoma. All but 2 of the glaucoma patients had been on topical timolol maleate, adrenaline and/or pilocarpine eye drops and/or oral medication (acetazolamide). The three groups did not differ from each other in age. The use of long-term glaucoma drugs is shown in Table 1 . The two glaucoma subgroups showed no differences in their pre-operative medication.

The aqueous humour samples were obtained during ocular surgery (extracapsular cataract extraction or trabeculectomy). All patients received $0.5 \%$

chloramphenicol (Oftan Akvakol, Leiras, Finland) drops six times daily in both eyes for 3 days before surgery. Drops containing 1\% dexamethasone alcohol with neomycin sulphate and polymyxine B sulphate (Maxitrol, Alcon, Puurs, Belgium) and 0.1\% diclofenac sodium (Naclof, Ciba Vision, Hettlingen, Switzerland) were applied four times on the day preceding surgery and once the morning before the operation. Those patients scheduled for an extracapsular cataract extraction were dilated with $1 \%$ cyclopentolate hydrochloride (Oftan Syklo, Leiras, Finland) and 10\% phenylephrine solutions (Oftan Metaoksedrin, Leiras, Finland) three times and with one drop $0.25 \%$ scopolaminehydrobromide (Oftan Scopolamin, Leiras, Finland) before the operation. The glaucoma patients with cataract received additionally $1 \%$ apraclonidine (Iopidine, Alcon, TX) drops twice on the pre-operative day and once on the day of surgery.

A needle was placed through the cornea into the anterior chamber at the limbus after a superior rectus bridle suture had been put in place to stabilise the globe and the intraocular pressure had been measured with a Schiötz tonometer. After aspiration of 50-100 $\mu$ l of aqueous humour with the 30 gauge needle, the sample was transferred to an Eppendorf centrifuge tube, stored at $-70{ }^{\circ} \mathrm{C}$ and thawed just before the assay. All other surgical manoeuvres were performed after the aqueous sample was withdrawn.

\section{Enzyme immunoassays for EDAcFN, pFN, tenascin and CGRP}

The concentrations of EDA-containing cFN (EDAcFN), tenascin and CGRP in aqueous humour samples were measured using the enzyme immunoassay (EIA) described in earlier communications; ${ }^{26-28}$ for $\mathrm{pFN}$ a similar assay was developed. For overnight coating of 96 well microtitration strips (High binding, Biohit Oy, Helsinki, Finland), $100 \mu \mathrm{l}$ of monoclonal antibodies (DH1 in EDAcFN, DB7 in tenascin, and 159AC1 in CGRP EIA, respectively) or polyclonal rabbit anti-human fibronectin antibodies (Dakopatts, Glostrup, Denmark) in pFN EIA was used and the wells washed four times with $0.02 \mathrm{M}$ phosphate-buffered saline (PBS), $\mathrm{pH} 7.0$, containing $0.1 \%$ Tween 20 prior to use. One hundred microlitres of samples $(1: 10)$ were added and incubated for $1 \mathrm{~h}$ at $37^{\circ} \mathrm{C}$. The unbound material was removed by washing four times with $0.02 \mathrm{M}$ PBS, and horseradish peroxidase (HRP)-conjugated specific monoclonal antibodies (BF12 in EDAcFN, EB2 in tenascin, and CD8 in CGRP EIA, respectively) or polyclonal $\mathrm{HRP}$-conjugated rabbit antihuman fibronectin antibodies (Dakopatts, Glostrup, Denmark) in pFN EIA were added.

After incubation for $1 \mathrm{~h}$ at $37^{\circ} \mathrm{C}$ the strips were washed, and the bound enzyme activity was visualised by the addition of $100 \mu$ l of substrate solution containing $\mathrm{H}_{2} \mathrm{O}_{2}$ and tetramethylbenzidine (TMB; Merck,

Darmstadt, Germany). Colour formation was allowed to proceed for $30 \mathrm{~min}$, after which $100 \mu \mathrm{l}$ of $4 \mathrm{M} \mathrm{H}_{2} \mathrm{SO}_{4}$ was added. The absorbances were measured in an Anthos

Table 1. The use of antiglaucoma medication in different patient groups

\begin{tabular}{|c|c|c|c|c|}
\hline Diagnosis & Beta-blocker & Adrenaline & Pilocarpine & Oral acetazolamide \\
\hline EXFG & $22 / 26(84.6 \%)$ & $5 / 26(19.2 \%)$ & $15 / 26(57.7 \%)$ & $7 / 26(26.9 \%)$ \\
\hline POAG $^{\mathrm{a}}$ & $26 / 28(92.9 \%)$ & $6 / 29(21.4 \%)$ & $15 / 28(53.6 \%)$ & $10 / 28(34.7 \%)$ \\
\hline Cataract & $0 / 13$ & $0 / 0$ & $0 / 0$ & $0 / 0$ \\
\hline
\end{tabular}

No statistically significant differences could be observed between the two glaucoma subgroups.

EXFG, exfoliative glaucoma; POAG, primary open-angle glaucoma.

${ }^{a}$ Data from one patient are missing. 
Table 2. The medians and ranges of plasma fibronectin ( $p F N)$ and cellular fibronectin (cFN) concentrations in different patient groups

\begin{tabular}{|c|c|c|c|c|c|}
\hline \multirow[b]{2}{*}{ Diagnosis } & \multirow[b]{2}{*}{$n$} & \multicolumn{2}{|c|}{$\mathrm{pFN}(\mu \mathrm{g} / \mathrm{ml})$} & \multicolumn{2}{|c|}{$\mathrm{cFN}(\mu \mathrm{g} / \mathrm{ml})$} \\
\hline & & Median & Range & Median & Range \\
\hline$\overline{\text { EXFG }}$ & 26 & $0.202^{*}$ & $0.012-1.787$ & $0.035^{*}$ & $0.000-0.361$ \\
\hline POAG & 29 & 0.094 & $0.000-1.078$ & 0.000 & $0.000-0.252$ \\
\hline Glaucoma & 55 & $0.134^{*}$ & $0.000-1.787$ & 0.009 & $0.000-0.361$ \\
\hline Cataract & 13 & 0.064 & $0.000-0.202$ & 0.000 & $0.000-0.031$ \\
\hline
\end{tabular}

Statistically significant difference $(p<0.05)$ when compared with the cataract group.

microtitration plate reader (Anthos Labtec, Salzburg, Austria) at $450 \mathrm{~nm}$. The detection limits of the $\mathrm{cFN}$ and pFN EIAs were $0.001 \mathrm{mg} / \mathrm{ml}$ and $0.005 \mathrm{mg} / \mathrm{ml}$, respectively. The interassay variabilities were below $10 \%$.

\section{Statistical analysis}

Because the distributions of the pFN and $\mathrm{cFN}$ concentrations were skewed, non-parametric Kruskal-Wallis one-way analysis of variance and Dunn's test for multiple comparisons were used. The results are presented as medians and ranges. $p$ values $<0.05$ were considered statistically significant.

\section{Results}

\section{Plasma fibronectin in aqueous humour}

About $87 \%$ of the total $\mathrm{FN}$ in the aqueous humour was due to the presence of $p F N$. The median $p F N$ and $c F N$ levels of different patient groups are presented in Table 2.

The pFN levels of patients with EXFG, POAG or cataract were compared ( $p=0.0004$; Table 3$)$. In multiple comparisons EXFG patients showed significantly higher pFN levels than cataract patients $(p<0.01)$ or POAG patients $(p<0.05)$. The pFN levels in the latter two groups were not statistically different from each other.

\section{Cellular fibronectin in aqueous humour}

When the cFN levels of the three groups were compared, $p$ was 0.0110 (Table 3 ). In multiple comparisons EXFG patients showed significantly higher $\mathrm{cFN}$ levels than cataract patients $(p<0.05)$ or POAG patients $(p<0.05)$. There was no statistical difference between $\mathrm{cFN}$ levels in POAG and cataract patients.

\section{Tenascin and CGRP in aqueous humour}

Neither tenascin nor CGRP was detected in the aqueous humour of any of our patients.

\section{Discussion}

The present study is in accordance with the finding of Kim et al. ${ }^{25}$ showing that the aqueous humour FN concentration of glaucoma patients is higher than that cataract patients. Since exfoliation is not mentioned in this study, we included two types of glaucoma patients in our study: those with primary open-angle glaucoma (POAG) and those with exfoliative glaucoma (EXFG). Our study further shows that it is the EXFG that is responsible for the difference in $\mathrm{pFN}$ concentration between glaucoma and control patients. Our results would be even more meaningful if the number of the patients in the cataract group had been closer to that of the glaucoma groups.

The higher levels of pFN in EXFG suggest the presence of a deficiency of the blood-aqueous barrier. This is supported by earlier data indicating that the aqueous protein concentration is significantly higher in eyes with exfoliation than in eyes with cataract or in eyes of POAG patients. ${ }^{29}$ The rupture in the blood-aqueous barrier for IgG and albumin in eyes with exfoliation and glaucoma has also been verified. ${ }^{30}$ We observed higher pFN and cFN levels in EXFG than in cataract and, furthermore, higher pFN and cFN levels in EXFG than in POAG. Not only does the blood-aqueous barrier seem to be more permeable in EXFG than in cataract or POAG, but also local production of cFN may be more pronounced in EXFG. The pre-operative drugs of the glaucoma and cataract groups were not identical, and this may have influenced our results. The pre-operative medication of the two glaucoma subgroups, on the other hand, was identical. Thus the differences in FN concentrations cannot be explained by damage to the blood-aqueous barrier caused by the pre-operative medication. It is worth mentioning that both $\mathrm{cFN}$ and pFN are components of disordered extracellular matrix of exfoliation material. ${ }^{31}$

Since it is an adhesive glycoprotein with binding sites for multiple molecules, ${ }^{32}$ FN may have a role in the pathogenesis of exfoliative glaucoma. It is present in all parts of the normal aqueous drainage channels.

Table 3. The levels of significance between the three patient groups in a Kruskal-Wallis one-way analysis of variance, and p values in Dunn's multiple comparisons when different patient groups are compared with each other

\begin{tabular}{|c|c|c|c|c|}
\hline \multirow[b]{2}{*}{ Patient groups } & \multicolumn{2}{|c|}{$\begin{array}{c}\text { Analysis of variance } \\
\text { (Kruskal-Wallis) }\end{array}$} & \multicolumn{2}{|c|}{$\begin{array}{c}\text { Multiple comparisons } \\
\text { (Dunn) }\end{array}$} \\
\hline & $\mathrm{pFN}$ & $\mathrm{cFN}$ & $\mathrm{pFN}$ & $\mathrm{cFN}$ \\
\hline $\begin{array}{l}\text { EXFG vs POAG } \\
\text { EXFG vs cataract } \\
\text { POAG vs cataract }\end{array}$ & 0.0004 & 0.01 & $\begin{array}{c}<0.05 \\
<0.01 \\
\text { NS }\end{array}$ & $\begin{array}{c}<0.05 \\
<0.05 \\
\text { NS }\end{array}$ \\
\hline
\end{tabular}


Increased concentrations have been detected in glaucomatous and aged eyes. ${ }^{1,2}$ The $\alpha_{3} \beta_{1}$ integrin complex, which is a potential FN receptor, ${ }^{33}$ has been demonstrated in the human chamber angle. ${ }^{34}$ Hence binding of particularly pFN to the inner wall of Schlemm's canal, the cribriform areas of the trabecular meshwork and juxtacanalicular tissues may further add to the increase in outflow resistance known to be markedly increased in glaucoma, especially EXFG. ${ }^{35}$ Blockage of a FN receptor by a peptide analogue (ArgGly-Asp) has been suggested as therapy for glaucoma. ${ }^{36}$

Transforming growth factor- $\beta$ (TGF- $\beta$ ) regulates the accumulation of extracellular matrix proteins such as FN. $^{37-39}$ Aqueous humour in glaucomatous eyes contains increased levels of TGF- $\beta_{2},{ }^{40}$ and hence may be involved in the obstruction of outflow pathways. Furthermore, urokinase and tissue-type plasminogen activators have been detected in the aqueous humour or trabecular meshwork. ${ }^{41-44}$ Plasminogen activators cleave plasminogen to yield plasmin, ${ }^{45}$ which in turn can cleave FN into smaller fragments. ${ }^{46}$ The altered balance between synthesis and degradation of the extracellular matrix in trabecular meshwork may be involved in the pathogenesis of glaucoma. Furthermore, proteolytic enzymes have been suggested to facilitate infiltration of exfoliative material and development of zonular fragility in exfoliative eyes. ${ }^{47}$

Tenascin is present in tear fluid, ${ }^{48}$ but was not found in the aqueous humour of any patient groups. It does not seem to be a component of the aqueous humour. CGRP was unexpectedly not found in any of the samples despite the low detection limit of our assay allowing its demonstration in tears. ${ }^{28}$ One explanation might be the presence of proteases in the aqueous humour, which might cleave CGRP into non-immunoreactive fragments. Further studies are needed to determine the role of naturally released CGRP in the control of intraocular pressure or modulation of glaucoma pathogenesis in humans.

The study was supported by Mary and Georg C. Ehrnrooth Foundation; Eye and Tissue Bank Foundation, Finland; Orion Corporation Research Foundation; The Friends of the Blind, Finland; Genex Oy, Helsinki, Finland; and the Finnish Medical Council.

\section{References}

1. Floyd BB, Cleveland PH, Worthen DM. Fibronectin in human trabecular drainage channels. Invest Ophthalmol Vis Sci 1985;26:797-804.

2. Murphy CG, Yun AJ, Newsome DA, Alvarado JA. Localization of extracellular proteins of the human trabecular meshwork by indirect immunofluorescence. Am J Ophthalmol 1987;104:33-43.

3. Tervo T, van Setten G-B, Lehto I, Tervo K, Tarkkanen A, Virtanen I. Immunohistochemical demonstration of tenascin in the normal human limbus with special reference to trabeculectomy. Ophthalmic Res 1990;22:128-33.

4. Terttunen J, Palkama A, Virtanen I, Uusitalo H. Immunohistochemical characterization of tenascin, laminin and collagen IV in human trabecular outflow channel. Invest Ophthalmol Vis Sci (Suppl) 1994;35:1845.
5. Tripathi BJ, Tripathi RC, Yang C, Millard CB, Dixit VM. Synthesis of a thrombospondin-like cytoadhesion molecule by cells of the trabecular meshwork. Invest Ophthalmol Vis Sci 1991;32:181-8.

6. Gong H, Trinkaus-Randall V, Freddo TF. Ultrastructural immunocytochemical localization of elastin in normal human trabecular meshwork. Curr Eye Res 1989;8:1071-82.

7. Umihira J, Nagata S, Nohara S, Hanai T, Usuda N, Segawa K. Localization of elastin in the normal and glaucomatous human trabecular meshwork. Invest Ophthalmol Vis Sci 1994;35:486-94.

8. Gonzalez-Avila G, Ginebra M, Hayakawa T, et al. Collagen metabolism in human aqueous humor from primary openangle glaucoma: decreased degradation and increased biosynthesis play a role in its pathogenesis. Arch Ophthalmol 1995;113:1319-23.

9. Tamkun JW, Hynes RO. Plasma fibronectin is synthesized and secreted by hepatocytes. J Biol Chem 1983;258:4641-7.

10. Vartio T, Laitinen L, Närvänen $\mathrm{O}$, et al. Differential expression of the ED sequence-containing form of cellular fibronectin in embryonic and adult human tissues. J Cell Sci 1987;88:419-30.

11. Gould VE, Martinez-Lacabe V, Virtanen L. Sahlin KM, Schwarz MM. Differential distribution of tenascin and cellular fibronectin in acute and chronic renal allograft rejection. Lab Invest 1992;67:71-9.

12. Babizhayev MA, Brodskaya MW. Fibronectin detection in drainage outflow system of human eyes in ageing and progression of open-angle glaucoma. Mech Ageing Dev 1989;47:145-57.

13. Yun AJ, Murphy CG, Polansky JR, Newsome DA, Alvarado JA. Proteins secreted by human trabecular cells: glucocorticoid and other effects. Invest Ophthalmol Vis Sci 1989;30:2012-22.

14. Chiquet-Ehrismann R, Mackie EJ, Pearson CA, Sakakura T. Tenascin: an extracellular matrix protein involved in tissue interactions during fetal development and oncogenesis. Cell 1986;47:131-9.

15. Erickson HP, Bourdon MA. Tenascin: an extracellular matrix protein prominent in specialized embryonic tissues and tumors. Annu Rev Cell Biol 1989;5:71-92.

16. Tervo K, van Setten G-B, Beuerman RW, Virtanen I, Tarkkanen A, Tervo T. Expression of tenascin and cellular fibronectin in the rabbit cornea after anterior keratectomy: immunohistochemical study of wound healing dynamics. Invest Ophthalmol Vis Sci 1991;32:2912-8.

17. van Setten G-B, Koch JW, Tervo K, et al. Expression of tenascin and fibronectin in the rabbit cornea after excimer laser surgery. Graefes Arch Clin Exp Ophthalmol 1992;230:178-83.

18. Terenghi G, Polak JM, Ghatei MA, et al. Distribution and origin of calcitonin gene-related peptide (CGRP) immunoreactivity in the sensory innervation of the mammalian eye. J Comp Neurol 1985;233:506-16.

19. Oksala O. Effects of calcitonin gene-related peptide and substance $\mathrm{P}$ on the regional blood flow in the cat eye. Exp Eye Res 1988;47:283-9.

20. Oksala O, Stjernschantz J. Effects of calcitonin gene-related peptide in the eye: a study in rabbits and cats. Invest Ophthalmol Vis Sci 1988;29:1006-11.

21. Wahlestedt C, Beding B, Ekman R, Oksala O, Stjernschantz J, Håkanson R. Calcitonin gene-related peptide in the eye: release by sensory nerve stimulation and effects associated with neurogenic inflammation. Reg Peptides 1986;16:107-15.

22. Oksala O, Stjernschanz J. Increase in outflow facility of aqueous humor in cats induced by calcitonin gene-related peptide. Exp Eye Res 1988;47:787-90.

23. Almegård B, Andersson SE. Vascular effects of calcitonin gene-related peptide (CGRP) and cholecystokinin (CKK) in the monkey eye. J Ocular Pharmacol 1993;9:77-84. 
24. Almegård B, Andersson SE. Outflow facility in the monkey eye: effects of calcitonin gene-related peptide, cholecystokinin, galatin, substance $P$ and capsaicin. Exp Eye Res 1990;51:685-9.

25. Kim KS, Lee BH, Kim IS. Measurement of fibronectin concentrations in human aqueous humor. Korean J Ophthalmol 1992;6:1-5.

26. Ylätupa S, Mertaniemi P, Haglund C, Partanen P. An improved method for quantification of extra domain A-containing cellular fibronectin (EDAcFN) in different body fluids. Clin Chim Acta 1995;234:79-90.

27. Ylätupa S, Mertaniemi P, Haglund C, Partanen P. Enzyme immunoassay for quantification of tenascin in biologic samples. Clin Biochem 1995;28:263-8.

28. Mertaniemi P, Ylätupa S, Partanen P, Tervo T. Increased release of immunoreactive calcitonin gene-related peptide (CGRP) in tears after excimer laser keratectomy. Exp Eye Res 1995;60:659-65.

29. Küchle M, Ho TS, Nguyen NX, Hannappel E, Naumann $\mathrm{GOH}$. Protein quantification and electrophoresis in aqueous humor of pseudoexfoliation eyes. Invest Ophthalmol Vis Sci 1994;35:748-52.

30. Moreno-Montanes J, Lajara Blesa J. IgG, albumin and total IgG index in the aqueous humour of eyes with pseudoexfoliation syndrome. Acta Ophthalmol Scand 1995;73:249-51.

31. Schlötzer-Schrehardt U, Dörfler S, Naumann GOH. Immunohistochemical localization of basement membrane components in pseudoexfoliation material of the lens capsule. Curr Eye Res 1992;11:343-55.

32. Ruoslahti E. Fibronectin and its receptors. Annu Rev Biochem 1988;57:375-413.

33. Ruoslahti E. Integrins. J Clin Invest 1991;87:1-5.

34. Tervo K, Päällysaho T, Virtanen I, Tervo T. Integrins in human anterior chamber angle. Graefes Arch Clin Exp Ophthalmol 1995;233:291-5.

35. Tarkkanen A. Pseudoexfoliation of the lens capsule: a clinical study of 418 patients with special reference to glaucoma, cataract and changes of the vitreous. Acta Ophthalmol (Copenh) 1962;Suppl 71:1-98.

36. Babizhayev MA, Brodskaya MW. Immunohistochemical monitoring of the effect of a synthetic fibronectin-like peptide (Arg-Gly-Asp) on the age-related changes in the isolated human corneoscleral tissue of glaucomatous eyes. Mech Ageing Dev 1993;72:1-12.
37. Roberts AB, Sporn MB, Assoian RK, et al. Transforming growth factor type beta: rapid induction of fibrosis and angiogenesis in vivo and stimulation of collagen formation in vitro. Proc Natl Acad Sci USA 1986;83:4167-71.

38. Ignotz RA, Massague J. Transforming growth factor- $\beta$ stimulates the expression of fibronectin and collagen and their incorporation into the extracellular matrix. J Biol Chem 1986;261:4337-45.

39. Ohji M, SundarRaj N, Thoft RA. Transforming growth factor- $\beta$ stimulates collagen and fibronectin synthesis by human corneal stromal fibroblasts in vitro. Curr Eye Res 1993;12:703-9.

40. Tripathi RC, Li J, Chan WFA, Tripathi BJ. Aqueous humor in glaucomatous eyes contains an increased level of TGF- $\beta_{2}$. Exp Eye Res 1994;59:723-8.

41. Park JK, Tripathi RC, Tripathi BJ, Barlow GH. Tissue plasminogen activator in the trabecular endothelium. Invest Ophthalmol Vis Sci 1987;28:1341-5.

42. Tripathi RC, Park JK, Tripathi BJ, Millard CB. Tissue plasminogen activator in human aqueous humor and its possible therapeutic significance. Am J Ophthalmol 1988;106:719-22.

43. Bernatchez SF, Tabatabay C, Belin D. Urokinase-type plasminogen activator in human aqueous humor. Invest Ophthalmol Vis Sci 1992;33:2687-92.

44. Smalley DM, Fitzgerald JE, Taylor DM, Cone RE, O'Rourke J. Tissue plasminogen activator activity in human aqueous humor. Invest Ophthalmol Vis Sci 1994;35:48-53.

45. Vassalli JD, Sappino AP, Belin D. The plasminogen activator/plasmin system. J Clin Invest 1991;88:1067-72.

46. Vaheri A, Salonen EM, Vartio T. Fibronectin in the formation and degradation of the pericellular matrix. Ciba Found Symp 1985;114:111-26.

47. Schlötzer-Schrehardt U, Naumann GOH. A histopathologic study of zonular instability in pseudoexfoliation syndrome. Am J Ophthalmol 1994;118:730-43.

48. Vesaluoma M, Ylätupa S, Mertaniemi P, Tervo K, Partanen P, Tervo $T$. Increased release of tenascin in tear fluid after photorefractive keratectomy. Graefes Arch Clin Exp Ophthalmol 1995;233:479-83. 